\title{
Role of l-arginine in the prevention of pre eclampsia in high-risk pregnancies.
}

\author{
Nadia Taj', Asma Sajid², Tehreem Rasheed ${ }^{3},{\text { Anam } \mathrm{Naz}^{4} \text {, Saba Javed }}^{5}$, Munazza Munir ${ }^{6}$
}

Article Citation: Taj N, Sajid A, Rasheed T, Naz A, Javed S, Munir M. Role of I-arginine in the prevention of pre eclampsia in high-risk pregnancies. Professional Med J 2022; 29(1):62-66. https://doi.org/10.29309/TPMJ/2022.29.01.5613

\begin{abstract}
Objective: To compare the efficacy of L-Arginine versus placebo in the prevention of pre eclampsia in high-risk pregnancies. Study Design: Randomized Control Trial. Setting: Department of Obstetrics and Gynecology, Nishtar Hospital Multan. Period: November 2019 to February 2019. Material \& Methods: A total of 130 women were included in the study. 65 patients were in L-arginine group or Group A while 65 patients were in placebo group or Group B. In group A, women were prescribed L-arginine 300 grams (Amino Whey Sachet) once a day until delivery and in group B; women were given homologated placebo (starch) once a day until delivery. Efficacy (no preeclampsia occurs during pregnancy) was noted from both groups and recorded. Mean \pm SD was presented for quantitative variables like age, gestational age, parity, duration of chronic hypertension, weight, height and BMI. Variables such as age, parity, hypertension, body mass index, gestational age and duration of hypertension were stratified to assess their effect on efficacy. Chi square test was used to make comparison of the efficacy in both groups as well as for post-stratification for both groups. A p value of less than or equal to 0.05 was taken as significant. Results: In L-arginine group efficacy was $92.3 \%$ as compared to $69.2 \%$ in placebo group ( $p<0.000$ ) Table-IV. Conclusion: It can be concluded that L-arginine when given orally at the dose of $300 \mathrm{~g}$ daily has a considerable role in prevention of pre-eclampsia in pregnant patients with high risk and also has a role in reduction of severity of pre-eclampsia.
\end{abstract}

Key words: Efficacy, L-Arginine, Preeclampsia.

\section{INTRODUCTION}

The exact causes of preeclampsia are unknown in patients with high-risk pregnancies, so there is no satisfactory treatment present. In recent studies it was clear that, in developing countries, during pregnancy preeclampsia is the main cause of morbidity and mortality of the mother and fetus. The percentage of pregnant women affected by preeclampsia around the world ranges from 2 to $8 \% .{ }^{1}$ Just as preeclampsia, women also suffer from hypertension during pregnancy which has become a common medical complication among pregnant females. ${ }^{2,3}$ Almost $70 \%$ of hypertensive pregnant women have preeclampsia and these complications cause 50,000 maternal deaths every year. ${ }^{4}$ Due to lesser access to the maternal health care center the maternal mortality rate is much higher in developing countries (15\%) as compared to that in developed countries (0$1.8 \%) .{ }^{5}$ In Pakistan $16 \%$ of maternal deaths due to preeclampsia complications are reported. ${ }^{6}$

L-arginine can be proved effective against preeclampsia by relieving systemic symptoms while the exact mechanism is still unknown. ${ }^{7,8}$ It is considered that during preeclampsia uterine spiral arteries are impaired which are improved by the use of L-arginine remodeling processes. In a study by Ekambaram ${ }^{9}$ and Stuehr ${ }^{10}$, it was suggested that L-arginine may have a role in L-arginine-nitric oxide pathway. In women with preeclampsia, impaired endothelium-dependent responses can be seen in isolated blood vessels. ${ }^{11}$ These results propose that the pathophysiological processes of preeclampsia are mediated impaired production of endothelial nitric oxide. Efficacy of L-arginine in prevention of preeclampsia was $93.9 \%$ to as that of placebo $(76.6 \%)$ in high risk pregnancies, as reported in a study of Camarena-Pulido EE et al. ${ }^{12}$
1. MBBS, FCPS, Senior Registrar Obs \& Gynae, Nishtar Medical University, Multan. 2. FCPS, Senior Medical Officer, Mukhtiar A Sheikh Hospital, Multan.

3. MBBS, FCPS, Consultant Obs \& Gynae, Mukhtiar A Sheikh Hospital, Multan

4. MBBS, Post Graduate Resident Obs \& Gynae, Nishtar Medical University, Multan

5. MBBS, Post Graduate Resident Obs \& Gynae, Nishtar Medical University, Multan.

6. MBBS, Post Graduate Resident Obs \& Gynae, Nishtar Medical University, Multan

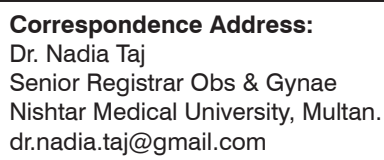

Correspondence Address:

Dr. Nadia Taj

Senior Registrar Obs \& Gynae

Nishtar Medical University, Multan. dr.nadia.taj@gmail.com

Article received on: Accepted for publication:

$14 / 07 / 2020$ $25 / 02 / 2021$ 
There are no such studies conducted among our general population earlier. Among the two groups, the group receiving L-arginine showed significant decrease in preeclampsia as compared to that of placebo group, in high risk pregnancies. Oral L-arginine administration has not shown any improvement in preeclampsia patients during randomized placebo controlled trials. Genetic variations and other different variables in foreign studies cannot be applied to local population. Hence, we studied the results over placebo and L-arginine group of highly risked pregnant patients and compared the results of both groups. My study will be helpful in the treatment of highly risked pregnancies with preeclampsia by using L-arginine.

\section{MATERIAL \& METHODS}

This study is a randomized controlled trial. It was conducted in the department of Obstetrics and Gynecology, Nishtar Hospital Multan, from $1^{\text {st }}$ November 2019 to 29 February 2019. The ethical board of the hospital gave the ethical approval for this study (GO/03-09/21). Sample size was calculated using the reference study where, $\mathrm{Cl}$ was taken as $95 \%$, power of study $80 \%$, proportion 1 98.9\%, and proportion 2 76.6\%. Proportion 1 was efficacy of L-arginine in group 1 and proportion 2 was efficacy in group 2 of patients. The calculated sample size was 130 . Two groups were designed with equal number of patients in each group i.e. group A and group B with 65 in each group. The sampling technique used was non-probability consecutive type of sampling. Women age 20-35 years, singleton pregnancy on ultrasound, gestational age $<20$ weeks on LMP, Parity 0-4 and High risk pregnancy took part in this study. On the contrary patients with the history of diabetes, $\mathrm{H} / \mathrm{O}$ renal disease and those who refused informed consent were excluded from the study.

All the patients gave informed consent where patients were explained about the details of participation in the study and were briefed on the benefits as well as risks of inclusion in the study. Randomization was conduct through sequentially number opaque envelopes generate from a random numbers table. 65 patients were in L-arginine group or Group A while 65 patients were in placebo group or Group B. In group A, women were prescribed L-arginine 300 grams (Amino Whey Sachet) once a day until delivery and in group $B$; women were given homologated placebo (starch) once a day until delivery. Efficacy (no preeclampsia occurs during pregnancy) was noted from both groups and recorded.

Data was analyzed with statistical analysis program (IBM-SPSS Version 22). Frequency and percentage was computed for qualitative variables like age groups, family history of hypertension and efficacy. Mean \pm SD was presented for quantitative variables like age, gestational age, parity, duration of chronic hypertension, weight, height and BMI. Variables such as age, parity, hypertension, body mass index, gestational age and duration of hypertension were stratified to assess their effect on efficacy. Chi square test was used to make comparison of the efficacy in both groups as well as for post-stratification for both groups. A p value of less than or equal to 0.05 was taken as significant.

\section{RESULTS}

In this study age ranged from 20 to 35 years with mean $33.500 \pm 1.75$ years in L-arginine group while $28.553 \pm 2.43$ yrs in Placebo group. In L-arginine group mean gestational age was $14.523 \pm 3.08$ weeks and $13.830 \pm 3.55$ weeks in Placebo group. Mean parity was $1.200 \pm 1.43$ in L-arginine group and $1.784 \pm 1.21$ in Placebo group, mean Duration of chronic hypertension was $1.984 \pm 0.99$ years in L-arginine group and $2.507 \pm 0.93$ years in placebo group, mean weight was $62.323 \pm 3.42 \mathrm{Kg}$ in L-arginine group and $62.646 \pm 6.11$ in placebo group. In L-arginine group mean height was $1.606 \pm 0.04$ meters and $1.586 \pm 0.07$ meters in placebo group. Similarly in L-arginine group mean BMI was $24.226 \pm 2.10$ $\mathrm{kg} / \mathrm{m}^{2}$ and $25.071 \pm 3.52 \mathrm{Kg} / \mathrm{m}^{2}$ in placebo group Table-I. In L-arginine group efficacy was $92.3 \%$ as compared to $69.2 \%$ in placebo group $(p<0.000)$ Table-IV. 


\begin{tabular}{|l|c|c|}
\hline \multicolumn{1}{|c|}{ Characteristics } & $\begin{array}{c}\text { Group A } \\
\mathbf{n = 6 5}\end{array}$ & $\begin{array}{c}\text { Group B } \\
\mathbf{n = 6 5}\end{array}$ \\
\hline Age (years) & $33.500 \pm 1.75$ & $28.553 \pm 2.43$ \\
\hline Gestational age (weeks) & $14.523 \pm 3.08$ & $13.830 \pm 3.55$ \\
\hline Parity & $1.200 \pm 1.43$ & $1.784 \pm 1.21$ \\
\hline $\begin{array}{l}\text { Duration of chronic } \\
\text { hypertension (years) }\end{array}$ & $1.984 \pm 0.99$ & $2.507 \pm 0.93$ \\
\hline Weight $(\mathrm{Kg})$ & $62.323 \pm 3.42$ & $62.646 \pm 6.11$ \\
\hline Height $(\mathrm{m})$ & $1.606 \pm 0.04$ & $1.586 \pm 0.07$ \\
\hline BMI $\left(\mathrm{Kg} / \mathrm{m}^{2}\right)$ & $24.226 \pm 2.10$ & $25.071 \pm 3.52$ \\
\hline
\end{tabular}

Table-I. Mean \pm SD of patients according to age, gestational age, parity, duration of chronic hypertension, weight, height and BMI. $n=130$

\begin{tabular}{|l|c|c|}
\hline $\begin{array}{c}\text { Family history } \\
\text { of hypertension }\end{array}$ & $\begin{array}{c}\text { Group A } \\
\mathbf{n = 6 5}\end{array}$ & $\begin{array}{c}\text { Group B } \\
\mathbf{n = 6 5}\end{array}$ \\
\hline Yes & $42(64.6 \%)$ & $39(60 \%)$ \\
\hline No & $23(35.4 \%)$ & $26(40 \%)$ \\
\hline Total & $65(100 \%)$ & $65(100 \%)$ \\
\hline
\end{tabular}

Table-III. Family history of hypertension.

\begin{tabular}{|c|c|c|c|}
\hline Efficacy & $\begin{array}{c}\text { Group A } \\
n=65\end{array}$ & $\begin{array}{c}\text { Group B } \\
n=65\end{array}$ & P-Value \\
\hline Yes & 60 (92.3\%) & $45(69.2 \%)$ & \multirow{3}{*}{0.000} \\
\hline No & $5(7.7 \%)$ & 20 (30.8\%) & \\
\hline Total & $65(100 \%)$ & $65(100 \%)$ & \\
\hline
\end{tabular}

For 1-3 years

\begin{tabular}{|l|c|c|c|}
\hline \multicolumn{3}{|c|}{ Efficacy } & \multirow{2}{*}{ P-Value } \\
\hline Group & Yes & No & \\
\hline L-arginine & $54(91.5 \%)$ & $5(8.5 \%)$ & \multirow{2}{*}{0.003} \\
\hline Placebo & $38(70.4 \%)$ & $16(29.6 \%)$ & \\
\hline For > 3 years & Yes & No & \\
\hline Group & $6(100 \%)$ & $0(0 \%)$ & \multirow{2}{*}{0.091} \\
\hline L-arginine & $7(63.6 \%)$ & $4(36.4 \%)$ & \\
\hline Placebo & & & \\
\hline
\end{tabular}

\section{DISCUSSION}

In our study, a group of patients with $7.7 \%$ frequency of preeclampsia, L-arginine decreased the rate of preeclampsia. In this group of patients L-arginine efficacy was $92.3 \%$. In a study done by Vadillo et $\mathrm{al}^{13}$ the results were same as that of our study, but they used half dose as compared to our. Side effects reported in their study included headache, dizziness, and palpitations, while no such effects were reported in our study. Dyspepsia was the only condition reported in our study was dyspepsia. As a result, in the patients with acid peptic ulcer, it was considered that physicians must deal them carefully while administering drugs. In our study it was seen that L-arginine can decrease the systolic, diastolic, and mean blood pressure. It was also noticed that a significant low dose of hypertensive drugs could be given in chronic hypertensive patients. The results were also comparable to that given by Facchinetti et al. $^{14} \mathrm{~A}$ significant decrease in cases of preeclampsia due to pregnancies late gestational period and favorable perinatal outcome was reported in current study. The results are similar as to those of Rytlewski et al. ${ }^{15}$, $\mathrm{s}$ results. Range of 58 to $94 \%$ recurring cases of preeclampsia was reported..$^{16}$ Therefore, results of our study showed that L-arginine is very effective in treatment of recurring of preeclampsia.

In each group patients, two patients were reported with gestational diabetes. On the other hand they had balanced diet and exercise regularly so that there was no need of use of insulin in these patients hence they were not removed from the study. Shim et al. ${ }^{17}$ coupled the incidence of preeclampsia with growth limitation of fetus and decrease in the growth factor in placenta. There were three cases of growth limitation of fetus in control group (placebo group) while one case among the patients in case group (L-arginine group) with preeclampsia was discovered. In a study by Noris et al. ${ }^{18}$ it was discussed that serum levels of ADMA or oxidative stress were not measured and it was assumed that NO production was increased by NOS2, avoid the formation of peroxynitrite. In several studies it was reported that L-arginine's high dose administration is helpful improving vascular functions. But in these studies patients had vascular modification as all of these patients were hypertensive and were receiving other pharmacological treatments. On the other hand in this study there were 3 patients with chronic hypertension in placebo group and 6 patients in L-arginine group, receiving pharmacological treatment which improved their ADMA levels. In our study results showed that effective replacement of arginine requires a dose of $300 \mathrm{~g}$ L-arginine which is due to increased metabolism of L-arginine to arginine through NO-independent 
pathways. When there are high levels of ADMA, L-arginine compete for enzyme NOS3. Hence elevation in the blood pressure is prevented by the use of L-arginine in preeclampsia patients with high risk factor. By the use of $300 \mathrm{~g}$ of dose we are able to avoid the effects of L-arginine and same level of efficacy will be maintained, which is the main advantage of this dose as per reported by different studies.

As in the Mexico there is large number of teenage pregnancies, therefore patients participated in our study are mostly young. There were 30\% teenage pregnancies reported according to data of Juan I. Manchaca Hospital in 2014 and all of them were at risk of development of preeclampsia. According to data of the Juan I. Manchaca Hospital ${ }^{12}$, 380 patients attending the hospital due pregnancy had preeclampsia and 20 had eclampsia, among these 200 were of age less than 20 years. As the benefits and cost of L-arginine are higher as compared to aspirin, but benefits of its use against preeclampsia exceeds the cost of treatment of preeclampsia. In our study it was clearly seen that good results were shown by L-arginine when administered to patients with preeclampsia at gestational age of less than 20 weeks. Efficacy of L-arginine in patients of gestational period upto 16 weeks is higher as compared to after $16^{\text {th }}$ week as per meta-analysis done. ${ }^{19}$ L-arginine is considered important drug to be given in patients with preeclampsia where no other choice proved efficacious, such as aspirin. There should be studies over combined efficacy of use of aspirin and L-arginine.

\section{CONCLUSION}

It can be concluded that L-arginine when given orally at the dose of $300 \mathrm{~g}$ daily has a considerable role in prevention of pre-eclampsia in pregnant patients with high risk and also has a role in reduction of severity of pre-eclampsia.

\section{Copyright $(25$ Feb, 2021.}

\section{REFERENCES}

1. Jeyabalan A. Epidemiology of preeclampsia: Impact of obesity. Nutr Rev. 2013; 71(1):10.1111/nure.12055.

2. Burke SD, Karumanchi SA. Spiral artery remodelling in preeclampsia revisited. Hypertension. 2013; 62:10134.
3. Camacho E, Silva JA, Matos MG. Actividad de las enzimas anti oxidantes en el rinon de la rata con preeclampsia experimental. Archivos Ven Farmacol Ter. 2011; 30:44-50.

4. Das R, Biswas S. Eclapmsia: The major cause of maternal mortality in eastern India. Ethiop $\mathrm{J}$ Health Sci. 2015; 25(2):111-6.

5. Jido TA. Ecalmpsia: Maternal and fetal outcome. Afr Health Sci. 2012; 12(2):148-52.

6. Shaheen B, Hassan L, Obaid M. Eclampsia a major cause of maternal and perinatal mortality: A prospective analysis at a tertiary care hospital of Peshawar [internet]. JPMA; [cited 2017 Oct 28]. Available from URL: http://www.jpma.org.pk/full_article_ text.php?article_id $=242$.

7. Al-Bayati MA, Ahmad MA, Khamas W. The potential effect of L-arginine on mice placenta. Adv Pharmacoepidemiol Drug Saf. 2014; 3:150.

8. Dorniak-Wall T, Grivell RM, Dekker GA. The role of L-arginine in the prevention and treatment of preeclampsia: A systematic review of randomized trials. J Hum Hypertens. 2014; 28:230-5.

9. Ekambaram P. HSP70 expression and its role in preeclamptic stress. Indian J Biochem Biophys. 2011; 48:243-55.

10. Stuehr DJ. Enzymes of the L-arginine to nitric oxide pathway. J Nutr. 2004; 134:2748S-51S.

11. Ghulmiyyah L, Sibai B. Maternal mortality from preeclampsia/eclampsia. Semin Perinatol. 2012; 36:56-9.

12. Camarena-Pulido EE, García-Benavides L, PanduroBarón JG, Pascoe-Gonzalez S, Madrigal-Saray AJ, García-Padilla FE, et al. Efficacy of L-arginine for preventing preeclampsia in high-risk pregnancies: A double-blind, randomized, clinical trial. Hypertens Pregnancy. 2016; 35(2):217-25.

13. Vadillo-Ortega F, Perichart-Perera O, Espino S, et al. Effect of supplementation during pregnancy with $\mathrm{L}$ arginine and antioxidant vitamins in medical food on preeclampsia in high risk population: Randomized controlled trial. BMJ. 2011; 342:d2901.

14. Facchinetti F, Saade GR, Neri I, Pizzi C, Longo M. L arginine supplementation in patients with gestational hypertension in pregnancy. Hypertens Pregn. 2007; 26(1):121-130. 
15. Rytlewski K. Effects of oral I arginine on the fetal condition and neonatal outcome in preeclampsia. Preliminary report. Pharmacol Toxicol. 2006; 99(2):146-152.

16. Hjarturdottir S, Leifsson BG, Steinthorsdottir V. Recurrence of hypertensive disorder in second pregnancy. Am J Obstet Gynecol. 2006; 194(4):916920.

17. Shim SS, Lee CH, Jun JK. Midtrimester maternal plasma concentrations of angiopoietin 1, angiopoietin 2, and placental growth factor in pregnant women who subsequently develop preeclampsia. Obstet Gynecol Sci. 2015; 58(1):10-16. doi:10.5468/ogs.2015.58.1.10.
18. Noris M, Todeshini M, Cassis P, et al. L arginine depletion in preeclampsia orients nitric oxide synthase toward oxidant species. Hypertension. 2004; 43:614-622.

19. Bujold E, Roberge S, Lacasse Y, et al. Prevention of preeclampsia and intrauterine growth restriction with aspirin started in early pregnancy: A metaanalysis. Obstet Gynecol. 2010; 116 (2Pt1):402-414. doi:10.1097/AOG.0b013e3181e9322a.

\begin{tabular}{|c|c|c|c|}
\hline \multicolumn{4}{|c|}{ AUTHORSHIP AND CONTRIBUTION DECLARATION } \\
\hline No. & Author(s) Full Name & Contribution to the paper & Author(s) Signature \\
\hline 1 & Nadia Taj & Idea Conception. & Navivej \\
\hline 2 & Asma Sajid & Manuscript Writing. & \\
\hline 3 & Tehreem Rasheed & Data collection. & \\
\hline 4 & Anam Naz & Data collection. & \\
\hline 5 & Saba Javed & Data analysis. & 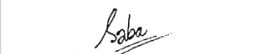 \\
\hline 6 & Munazza Munir & Proof reading. & \\
\hline
\end{tabular}

